\title{
Lack of microsatellite instability in gastrointestinal stromal tumors
}

\author{
NATHÁLIA C. CAMPANELLA ${ }^{1}$, CRISTOVAM SCAPULATEMPO-NETO ${ }^{1,2}$, \\ LUCAS FARIA ABRAHÃO-MACHADO ${ }^{2}$, ANTÔNIO TALVANE TORRES DE OLIVEIRA ${ }^{3}$, \\ GUSTAVO N. BERARDINELLI ${ }^{1}$, DENISE PEIXOTO GUIMARÃES ${ }^{1,4}$ and RUI M. REIS ${ }^{1,5,6}$
}

${ }^{1}$ Molecular Oncology Research Center; Departments of ${ }^{2}$ Pathology, ${ }^{3}$ Surgery and ${ }^{4}$ Endoscopy, Barretos Cancer Hospital,
Barretos, São Paulo 14784-400, Brazil; ${ }^{5}$ Life and Health Sciences Research Institute, Health Sciences School;
${ }^{6}$ Life and Health Sciences Research Institute/3B's-PT Government Associate Laboratory,
University of Minho, Guimarães, Braga 4704-553, Portugal

Received February 10, 2017; Accepted June 9, 2017

DOI: $10.3892 / 01.2017 .6884$

\begin{abstract}
The microsatellite instability (MSI) phenotype may constitute an important biomarker for patient response to immunotherapy, particularly to anti-programmed death-1 inhibitors. MSI is a type of genomic instability caused by a defect in DNA mismatch repair (MMR) proteins, which is present mainly in colorectal cancer and its hereditary form, hereditary nonpolyposis colorectal cancer. Gastrointestinal stromal tumor (GIST) development is associated with activating mutations of KIT proto-oncogene receptor tyrosine kinase $(K I T)$ or platelet-derived growth factor receptor $\alpha$ (PDGFRA), which are oncogenes that predict the response to imatinib mesylate. In addition to KIT/PDGFRA mutations, other molecular alterations are important in GIST development. In GISTs, the characterization of the MSI phenotype is scarce and the results are not consensual. The present study aimed to assess MSI in a series of 79 GISTs. The evaluation of MSI was performed by pentaplex polymerase chain reaction comprising five markers, followed by capillary electrophoresis. The expression of MMR proteins was evaluated by immunohistochemistry. Regarding the KIT/PDGFRA/B-Raf proto-oncogene, serine/threonine kinase molecular profile of the 79 GISTs, $83.6 \%$ of the tumors possessed KIT mutations, $10.1 \%$ had PDGFRA mutations and $6.3 \%$ were triple wild-type. The mutated-PDGFRA cases were associated with gastric location and a lower mitotic index compared with KIT-mutated and wild-types, and these patients were more likely to be alive and without cancer. MSI analysis identified 4 cases with instability in one marker, however, additional evaluation of normal tissue and immunohistochemical staining of MMR proteins confirmed their microsatellite-stable nature. The results of
\end{abstract}

Correspondence to: Dr Rui M. Reis, Molecular Oncology Research Center, Barretos Cancer Hospital, 1331 Antenor Duarte Vilela Street, Barretos, São Paulo 14784-400, Brazil

E-mail: ruireis.hcb@gmail.com

Key words: gastrointestinal stromal tumor, microsatellite instability, KIT, platelet-derived grow th factor receptor $\alpha$, immunotherapy the present study indicated that MSI is not involved in GIST tumorigenesis and, therefore, cannot serve as a biomarker to immunotherapy response in GIST.

\section{Introduction}

Microsatellite instability (MSI) status has drawn attention as a guide to immunotherapy against different types of tumor (1). Immune checkpoint inhibitors represent a significant advance in precision medicine, inducing durable tumor responses even in patients with late-stage cancer who have failed to respond to multiple previous lines of therapy $(1,2)$. Anti-programmed death (PD)-1 inhibitors, including pembrolizumab, are humanized monoclonal antibodies which block the interaction between PD-1 and its ligands, PD-L1 and PD-L2, and allow T cells to kill the tumor cells (1).

Notably, a phase II study (NCT01876511) in metastatic carcinomas demonstrated that the MSI phenotype constituted an important biomarker for patient response to immunotherapy (1). Most notably, the study revealed that immune checkpoint proteins, including PD-1 and PD-L1, were significantly upregulated in tumors with MSI, enabling them to survive. In MSI colorectal cancer (CRC), PD-L1 is expressed on tumor-infiltrating lymphocytes and/or myeloid cells as opposed to tumor cells $(1,2)$.

MSI is characterized by widespread somatic alterations in the length of nucleotide repeat sequences, which are known as microsatellites (3). The MSI phenotype is a marker of defects in the DNA mismatch repair (MMR) system during DNA replication $(3,4)$. The MSI phenotype is present in all cases of hereditary nonpolyposis CRC syndrome, as well as $\sim 15 \%$ of sporadic CRC, while it is less frequently observed in other tumors, including gastric, biliary tract, pancreas, ovary, prostate and small intestine tumors $(1,5)$. In CRC, the presence of MSI is also associated with a number of clinicopathological features, including proximal location, poorly-differentiated tumors, low frequency of distant metastases and an improved prognosis (6).

Gastrointestinal stromal tumors (GISTs) are the most common mesenchymal neoplasms of the gastrointestinal tract (7), with a global annual incidence of 11-18 per million $(8,9)$. GISTs are considered to originate from the 
interstitial cells of Cajal, or a common stem/precursor cell $(8,10)$, and usually arise in the stomach $(40-70 \%)$ or small intestine (20-40\%), and less frequently in the esophagus, colon and rectum $(8,11)$. GISTs also occur elsewhere within the abdominal cavity, primarily in the omentum, mesentery or retroperitoneum ( $<5 \%$ of all GISTs), and these are referred to as extra-gastrointestinal tract tumors $(12,13)$. Histologically, the spectrum of morphology includes spindle, epithelioid or mixed cells (14).

The malignant potential of GISTs ranges from entirely benign to aggressive tumors. However, $40 \%$ of GISTs that are localized at the time of diagnosis eventually metastasize (13). The metastatic dissemination has a predilection to the liver, omentum, peritoneum and other intra-abdominal sites (13). The prognosis of patients with GISTs is based on criteria established by the Armed Forces Institutes of Pathology (AFIP) criteria (15), including tumor location, size and mitotic index. This criterion ranks the patients as benign, very low, low, intermediate and high risk (8).

The majority of GISTs are positive for the proto-oncogene receptor tyrosine kinase (KIT) protein (anti-CD117 is used to identify KIT), and this positivity acts as a crucial diagnostic marker for these tumors $(8,16)$. KIT is a member of the type III receptor tyrosine kinase family, and the binding of its growth factor, stem cell factor (SCF), to the extracellular domain results in dimerization of the receptor and downstream activation of mitogen-activated protein kinase, phosphatidylinositol 3-kinase and Janus kinase/signal transducers and activators of transcription pathways (13).

KIT gene mutations are present in $70-80 \%$ of GIST cases (17). These oncogenic mutations result in the constitutive activation of the receptor and consequently, the activation of intracellular pathways (17). KIT mutations typically affect the juxtamembrane domain encoded by exon 11 (70\% of cases), the extracellular domain encoded by exon 9 (6-15\%) and the kinase I and II domains encoded by exons 13 and 17 $(2 \%)(17,18)$. In particular, deletions have been associated with a worse clinical outcome compared with other types of exon 11 mutation, with shorter progression-free and overall survival times (9). In addition, GISTs harboring KIT exon 9 mutations are characterized by small bowel location, aggressive clinical characteristics $(9,19)$ and decreased sensitivity to first line therapy compared with KIT exon 11 mutant tumors (9).

Another member of the tyrosine kinase receptor family, platelet-derived growth factor receptor $\alpha$ (PDGFRA), is also involved in GIST pathogenesis $(16,20)$. Mutations in the PDGFRA gene occur in 5-7\% of cases, in domains which are similar to those in the KIT gene (16,21). GISTs harbor mutations in the PDGFRA juxtamembrane domain (encoded by exon 12), the ATP-binding domain (encoded by exon 14) or the activation loop (encoded by exon 18) (21). The majority of GISTs with mutated-PDGFRA have a distinct phenotype, including gastric location, epithelioid morphology, variable/absent KIT expression as determined by immunohistochemistry and an indolent clinical course (22). In addition, mutations in exon 18 of PDGFRA are associated with a lack of response to imatinib therapy (21). Consistent with their functional overlap, KIT and PDGFRA mutations are mutually exclusive in GISTs $(8,16)$.

Between $10-15 \%$ of GISTs are KIT or PDGFRA wild-type (22). These tumors form a heterogeneous group, a
Table I. Clinicopathological features of gastrointestinal stromal tumors.

Variable

Patients, n (\%)

Sex

Female

$41(46.6)$

Male

47 (53.4)

Histological subtype

Spindle

$67(81.7)$

Epithelioid

$12(14.6)$

Mixed

Primary localization

Esophagus

1 (1.1)

Stomach

$44(50.0)$

Small intestine

25 (28.4)

Rectum

$6(6.9)$

Mesentery

$1(1.1)$

Retroperitoneum

$6(6.9)$

Colon

$1(1.1)$

Others $^{\mathrm{a}}$

4 (4.5)

Tumor size

$\leq 5 \mathrm{~cm}$

$28(37.3)$

$5.1-10 \mathrm{~cm}$

$22(33.3)$

$>10 \mathrm{~cm}$

25 (29.3)

Mitotic index

$\leq 5$

$39(58.2)$

$>5$

$25(37.3)$

6-10

AFIP risk classification

Benign

7 (11.3)

Very low

$7(11.3)$

Low

$7(11.3)$

Intermediate

$9(14.5)$

High

$32(51.6)$

Imatinib

Yes

$44(95.7)$

No

Local disease recurrence

Absent

$66(77.6)$

Present

$19(22.4)$

Metastasis

Absent

$47(54.7)$

Present

39 (45.5)

KIT/PDGFRA/BRAF mutation status

KIT

66 (83.6)

PDGFRA

$8(10.1)$

$B R A F$

$0(0.0)$

Wild-type

5 (6.3)

Current status

Mortality due to cancer 
Table I. Continued.

Variable

Patients, n (\%)

Current status

Mortality due to other causes

Alive with cancer

Alive without cancer

AFIP, Armed Forces Institutes of Pathology; KIT, KIT proto-oncogene receptor tyrosine kinase; PDGFRA, platelet-derived growth factor receptor $\alpha$. ${ }^{a}$ Other localizations included rectovagina (2/4), vagina (1/4), and unknown (1/4).

number of which are driven by oncogenic mutations acting downstream of the receptor kinases, such as B-Raf proto-oncogene, serine/threonine kinase $(B R A F)$ mutations (described in $1.3 \%$ of all tumors) $(23,24)$. A previous study demonstrated that wild-type GISTs exhibit a different genetic background, including mutation in succinate dehydrogenase (21). In either of these cases, there is poor response to first line therapy (9).

Molecular-targeted agents are being utilized as first line treatment for GISTs, including imatinib mesylate and sunitinib maleate. These two agents are KIT/PDGFRA competitive inhibitors that stabilize the inactivated form of the receptors, inhibiting downstream signaling activation (25-27). The median survival time for patients with advanced disease treated with imatinib is 5 years, with $34 \%$ of patients surviving $>9$ years (8). Despite this, the vast majority $(\geq 80 \%)$ of patients eventually develop secondary resistance (13). Acquired mutations in KIT or PDGFRA usually occur in the kinase domain and interfere with drug binding, causing resistance $(9,21)$. The majority of mutations in exon 9 are 6-nucleotide duplications encoding Ala502-Tyr503, which require twice the normal dose of imatinib ( $800 \mathrm{mg}$ /day) for optimal clinical results. In the PDGFRA gene, the most common mutation is a missense mutation in exon 18, which leads to substitution of Asp to Val (termed D842V) $(19,28)$. This mutation is usually resistant to treatment with imatinib $(19,28)$.

In GISTs, the characterization of MSI is limited and the results are controversial (29-31). Therefore, the present study aimed to assess the presence and frequency of MSI using an accurate methodology in a series of 88 Brazilian GISTs, and investigated the association with clinicopathological features of patients.

\section{Patients and methods}

Patient population and tissue samples. The present study analyzed 88 patients submitted to resection at Barretos Cancer Hospital (São Paulo, Brazil) between January 1989 and December 2012. A total of 79 primary GISTs were included in the KIT/PDGFRA molecular test and MSI analysis. The other 9 cases were excluded due to poor DNA quality and lower quantity. Clinicopathological data of patients were retrospectively obtained, including age, sex, tumor localization and risk classification (according to AFIP criteria), local disease recurrence, metastasis, chemotherapy and follow-up status (as of March 2015). In addition, information concerning GIST molecular status (KIT, PDGFRA and BRAF mutations) was previously reported for 60 cases $(32,33)$. The clinical and molecular data are summarized in Table I.

The average age of the individuals was $57 \pm 12.4$ years old. The most common histological subtype was spindle cells, and the most common primary localization was the stomach, followed by small intestine, rectum and retroperitoneum, (Table I). The tumors were classified as high risk in $51.6 \%$ of cases and the majority of patients were treated with an oral administration of $400 \mathrm{mg}$ of imatinib. Only 2 patients were treated with 5-fluorouracil and/or etoposide. The majority of patients $(54.7 \%)$ did not experience local recurrence or metastasis. Of those that did, liver $(66.7 \%)$ and lung $(7.7 \%)$ were the most common sites of metastasis (Table I).

The present study was approved by the local ethical committees (approval no. 554/2011) of Barretos Cancer Hospital. The ethics committee of our institution authorized that no patient consent was required due to the retrospective nature of the study.

DNA isolation. DNA from samples that had been fixed in $10 \%$ formalin for $12-24 \mathrm{~h}$ at room temperature and then paraffin-embedded was retrieved from $5-\mu \mathrm{m}$ cuts, following careful macrodissection of the tumor area and ensuring the presence of $>75 \%$ of neoplastic cells. DNA extraction was performed using the QIAamp DNA Micro kit (Qiagen, Inc., Valencia, CA, USA), following the manufacturer's protocol, quantified by NanoDropVR 2000 (Thermo Fisher Scientific, Inc., Waltham, MA, USA) and stored at $-20^{\circ} \mathrm{C}$ until subsequent genetic analysis.

KIT/PDGFRA/BRAF mutations. KIT and PDGFRA mutational status was analyzed by polymerase chain reaction (PCR) amplification and subsequent DNA sequencing of exons 9, 11, 13 and 17 to KIT and exon 12, 14 and 18 to PDGFRA, as previously described $(32,33)$.

Tumors with wild-type KIT and PDGFRA mutations were analyzed for the presence of exon $15 B R A F V 600 E$ mutations as previously described (24). The quality of PCR products was confirmed with $1 \%$ agarose gel electrophoresis. DNA sequencing of the PCR product was performed using the BigDye Terminator version 3.1 cycle sequencing kit (Applied Biosystems; Thermo Fisher Scientific, Inc.) and an ABI 3500XL Genetic Analyzer (Applied Biosystems; Thermo Fisher Scientific, Inc.) in accordance with manufacturer's protocol.

MSI analysis. The MSI evaluation was performed using a multiplex PCR comprising five quasi-monomorphic mononucleotide repeat markers (BAT-25, BAT-26, NR-21, NR-24 and NR-27) as previously reported (34-36). The primer sequences used were described in previous studies $(34,35)$. Each antisense primer was end labeled with a fluorescent dye: 6-carboxyfluorescein for BAT-26 and NR-21; 2'-chloro-7'-phenyl-1,4-dichloro-6-carboxyfluorescein for BAT-25 and NR-27; and 2,7,8-benzo-5-fluoro-2,4,7-trichloro-5-carboxyfluorescein for NR-24. PCR was performed using the Qiagen Multiplex PCR kit (Qiagen, Inc.), with $1 \mu \mathrm{l}$ DNA at $50 \mathrm{ng} / \mathrm{ml}$ and the following thermocycling conditions: 
Table II. Association between KIT/PDGFRA mutation status and clinicopathological features of gastrointestinal stromal tumors.

\begin{tabular}{|c|c|c|c|c|}
\hline Variable & KIT mutation, n (\%) & PDGFRA mutation, $\mathrm{n}(\%)$ & Wild-type, n (\%) & P-value \\
\hline Sex & & & & 1.000 \\
\hline Female & $32(48.5)$ & $4(50.0)$ & $2(40.0)$ & \\
\hline Male & $34(51.5)$ & $4(50.0)$ & $3(60.0)$ & \\
\hline Primary localization & & & & 0.398 \\
\hline Esophagus & $1(1.5)$ & 0 & 0 & \\
\hline Stomach & $29(43.9)$ & $8(100)$ & $4(80)$ & \\
\hline Small intestine & $20(30.3)$ & 0 & 0 & \\
\hline Rectum & $5(7.6)$ & 0 & $1(20)$ & \\
\hline Mesentery & $1(1.5)$ & 0 & 0 & \\
\hline Retroperitoneum & $6(9.1)$ & 0 & 0 & \\
\hline Other & $4(6.1)$ & 0 & 0 & \\
\hline Tumor size & & & & 0.963 \\
\hline$\leq 5 \mathrm{~cm}$ & $19(37.3)$ & $4(50.0)$ & $2(50.0)$ & \\
\hline $5.1-10 \mathrm{~cm}$ & $13(25.5)$ & $2(25.0)$ & $1(25.0)$ & \\
\hline$>10 \mathrm{~cm}$ & $19(37.3)$ & $2(25.0)$ & $1(25.0)$ & \\
\hline Mitotic index & & & & 0.018 \\
\hline$\leq 5$ & $24(51.1)$ & $6(75.0)$ & $3(60.0)$ & \\
\hline $5.1-10 \mathrm{~cm}$ & $1(2.1)$ & $2(25.0)$ & $0(0.0)$ & \\
\hline$>10$ & $22(46.8)$ & $0(0.0)$ & $2(40.0)$ & \\
\hline AFIP risk classification & & & & 0.198 \\
\hline Benign & $3(7.1)$ & $1(12.5)$ & $1(20.0)$ & \\
\hline Very low & $5(11.9)$ & $2(25.0)$ & $0(0.0)$ & \\
\hline Low & $5(11.9)$ & $1(12.5)$ & $0(0.0)$ & \\
\hline Intermediate & $4(9.5)$ & $2(25.0)$ & $2(40.0)$ & \\
\hline High & $25(59.5)$ & $2(25.0)$ & $2(40.0)$ & \\
\hline Metastasis & & & & 0.097 \\
\hline Absent & $34(52.3)$ & $7(87.5)$ & $4(80.0)$ & \\
\hline Present & $31(47.7)$ & $1(12.5)$ & $1(20.0)$ & \\
\hline Status at last follow-up & & & & 0.010 \\
\hline Alive without cancer & $16(25.4)$ & $7(87.5)$ & $3(60.0)$ & \\
\hline Alive with cancer & $24(38.1)$ & $0(0.0)$ & $0(0.0)$ & \\
\hline Mortality due to cancer & $21(33.3)$ & $1(12.5)$ & $2(40.0)$ & \\
\hline Mortality due to other causes & $2(3.2)$ & $0(0.0)$ & $0(0.0)$ & \\
\hline
\end{tabular}

AFIP, Armed Forces Institutes of Pathology; KIT, KIT proto-oncogene receptor tyrosine kinase; PDGFRA, platelet-derived growth factor receptor $\alpha .{ }^{a}$ Fisher's exact test.

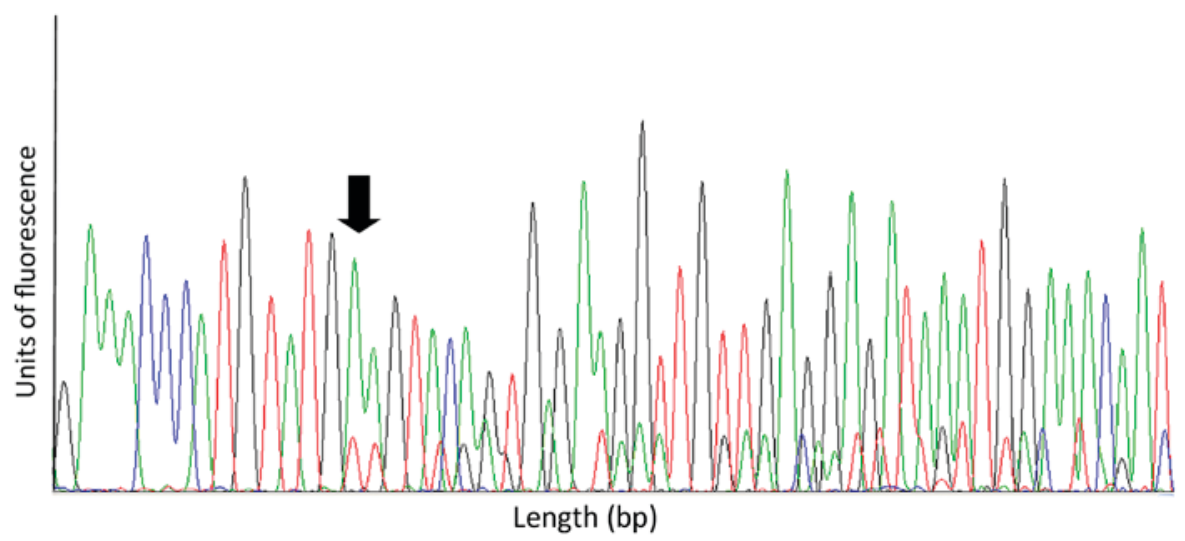

Figure 1. Electropherogram of KIT-mutated gastrointestinal stromal tumor (exon 11, p.Glu554_Val559del). 


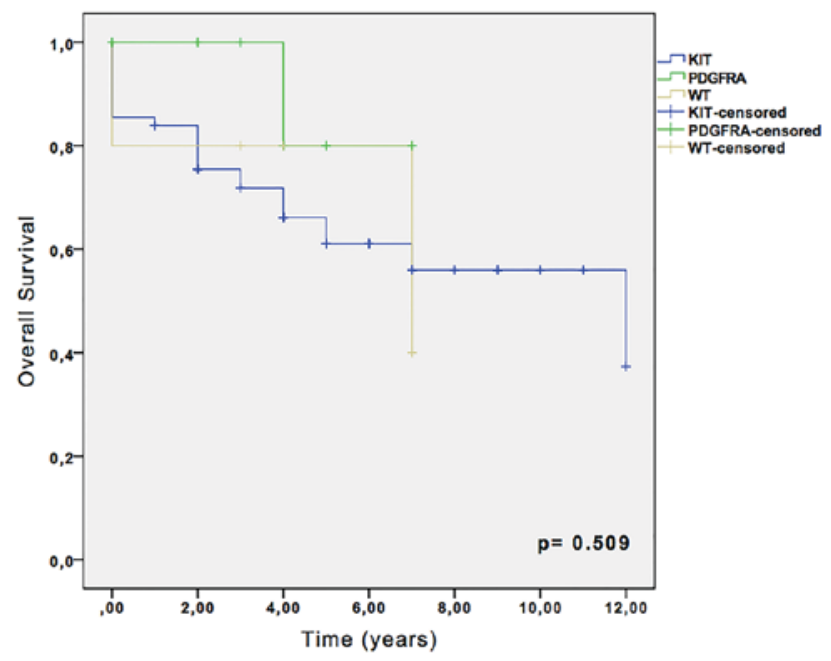

Figure 2. Overall survival for KIT and PDGFRA-mutated and wild-type GISTs.

$15 \mathrm{~min}$ at $95^{\circ} \mathrm{C} ; 40$ cycles of $95^{\circ} \mathrm{C}$ for $30 \mathrm{sec} ; 55^{\circ} \mathrm{C}$ for $90 \mathrm{sec}$ and $72^{\circ} \mathrm{C}$ for $30 \mathrm{sec}$; and a final extension at $72^{\circ} \mathrm{C}$ for $40 \mathrm{~min}$. PCR products were then submitted to capillary electrophoresis on an ABI 3500XL Genetic Analyzer (Applied Biosystems; Thermo Fisher Scientific, Inc.) according to the manufacturer's protocol, and the results were analyzed using GeneMapper v4.1 software (Applied Biosystems; Thermo Fisher Scientific, Inc.). In all analyses, the DNA from the HCT-15 cell line $\left(\mathrm{ATCC}^{\circledR}\right.$ CCL-225 ${ }^{\mathrm{TM}}$; American Type Culture Collection, Manassas, VA, USA) (MSI-high) was used as a positive control for MSI.

A previous study by our group determined the quasimonomorphic variation range of each marker for the Brazilian population (36). Accordingly, samples were considered MSI-high when two or more markers were altered, MSI-low when one marker was altered and microsatellite stable (MSS) in the absence of instability. In the MSI-low cases, validation by analysis of normal tissue or the immunohistochemistry of the MMR enzymes in tumor tissue was recommended (36).

MMR immunohistochemistry. Briefly, $10 \%$ formalin fixed (for 12-24 h at room temperature) paraffin-embedded tissue specimens were cut into $4-\mu \mathrm{m}$ sections, which were deparaffinized by heating $\left(75^{\circ} \mathrm{C}\right.$ for $4 \mathrm{~min}$ ) and then were transferred to Autostainer Link 48 equipment (Dako; Agilent Technologies, Inc. Santa Clara, CA, USA) (37). The antigen retrieval process was performed in Tris-EDTA buffer $\left(\mathrm{pH} \mathrm{9.0)}\right.$ at $97^{\circ} \mathrm{C}$ for 20 min. The EnVision ${ }^{\mathrm{TM}}$ FLEX Wash Buffer (Dako; Agilent Technologies, Inc.) contained Tris with Tween-20 (pH 7.6). Endogenous peroxidases were blocked at room temperature with EnVision $^{\mathrm{TM}}$ FLEX Peroxidase-Blocking reagent for $20 \mathrm{~min}$. The primary rabbit polyclonal anti-human antibodies used in the present study were as follows: Anti-mutL homolog 1 (MLH1; dilution, 1:100; clone G168-728, ref. 285M-1); anti-mutS homolog 2 (MSH2; dilution, 1:100; clone G219-1129, ref. 286M-1); anti-PMS1 homolog 2, mismatch repair system component (PMS2; dilution, 1:25; clone EPR3947, ref. 288R-1); and anti-mutS homolog 6 (MSH6; dilution, 1:600; clone 44, ref. 287M-1). All primary antibodies were obtained from Dako (Agilent Technologies,

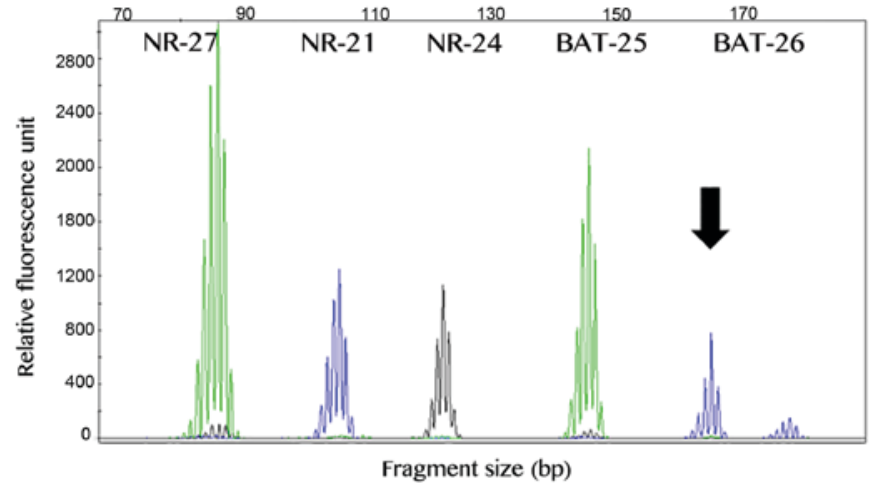

Figure 3. Electropherogram of fragment analysis in a representative gastrointestinal stromal tumor case, with the marker BAT-26 altered ( 9 nucleotides deletion, arrow).

Inc.) and were incubated at room temperature for $20 \mathrm{~min}$. The secondary antibody was the EnVision ${ }^{\mathrm{TM}}$ FLEX/horseradish peroxidase anti-rabbit and anti-mouse $\operatorname{IgG}(<10 \mu \mathrm{g} / \mathrm{ml})$ in $10 \%$ animal serum in TBS (ref. RE7111; Agilent Technologies, Inc.), which was incubated at room temperature with the samples for $20 \mathrm{~min}$. EnVision DAB solution was used for immunostaining visualization, and was incubated at room temperature with the samples for $10 \mathrm{~min}$. Slides were counterstained with Hematoxylin of Harris (EP-101071; EasyPath, São Paulo, Brazil) at room temperature for $5 \mathrm{~min}$, according to manufacturer's protocol. A light microscope was used to analyze all specimens at magnification, x100-400.

Statistical analysis. Associations between molecular and clinical data from patients were analyzed using the $\chi^{2}$ test or Fisher's test. Cumulative survival probabilities were calculated using the Kaplan-Meier method. Differences between survival rates were tested with the log-rank test. SPSS 19.0 software (IBM SPSS, Armonk, NJ, USA) was used for all statistical analysis. $\mathrm{P}<0.05$ was considered to indicate a statistically significant difference.

\section{Results}

Molecular and clinical profile of GISTs. Of the 88 GISTs analyzed, 9 cases were excluded due to poor DNA quality and lower quantity, leaving a total of 79 GIST cases. KIT mutations were observed in $83.6 \%(66 / 79)$ of cases and $10.1 \%(8 / 79)$ of cases exhibited PDGFRA mutations (Table I). None of the remaining cases $(\mathrm{n}=5)$ exhibited $B R A F$ mutations, leading to a frequency of $6.3 \%(5 / 79)$ wild-type cases. The KIT mutation was located at exon 11 in 58 cases $(87.9 \%)$, exon 9 in 6 cases (9.1\%) and exon 17 in 2 cases (3.0\%) Fig. 1 depicts a representative electropherogram of a mutation in exon 11. Regarding PDGFRA, 5 cases were mutated at exon 18 (62.5\%), 1 case was mutated at exon $12(12.5 \%)$ and 2 cases were mutated at exons 12 and 18 (25.0\%).

The associations between KIT/PDGFRA mutation status and GIST clinicopathological features are listed in Table II. All PDGFRA-mutated GISTs had a gastric location and PDGFRA-mutation status was significantly associated with lower mitotic index $(\mathrm{P}=0.018$; Table II). The average follow-up period was $4.3 \pm 3.2$ years, and $87.5 \%$ of patients with $P D G F R A$ 

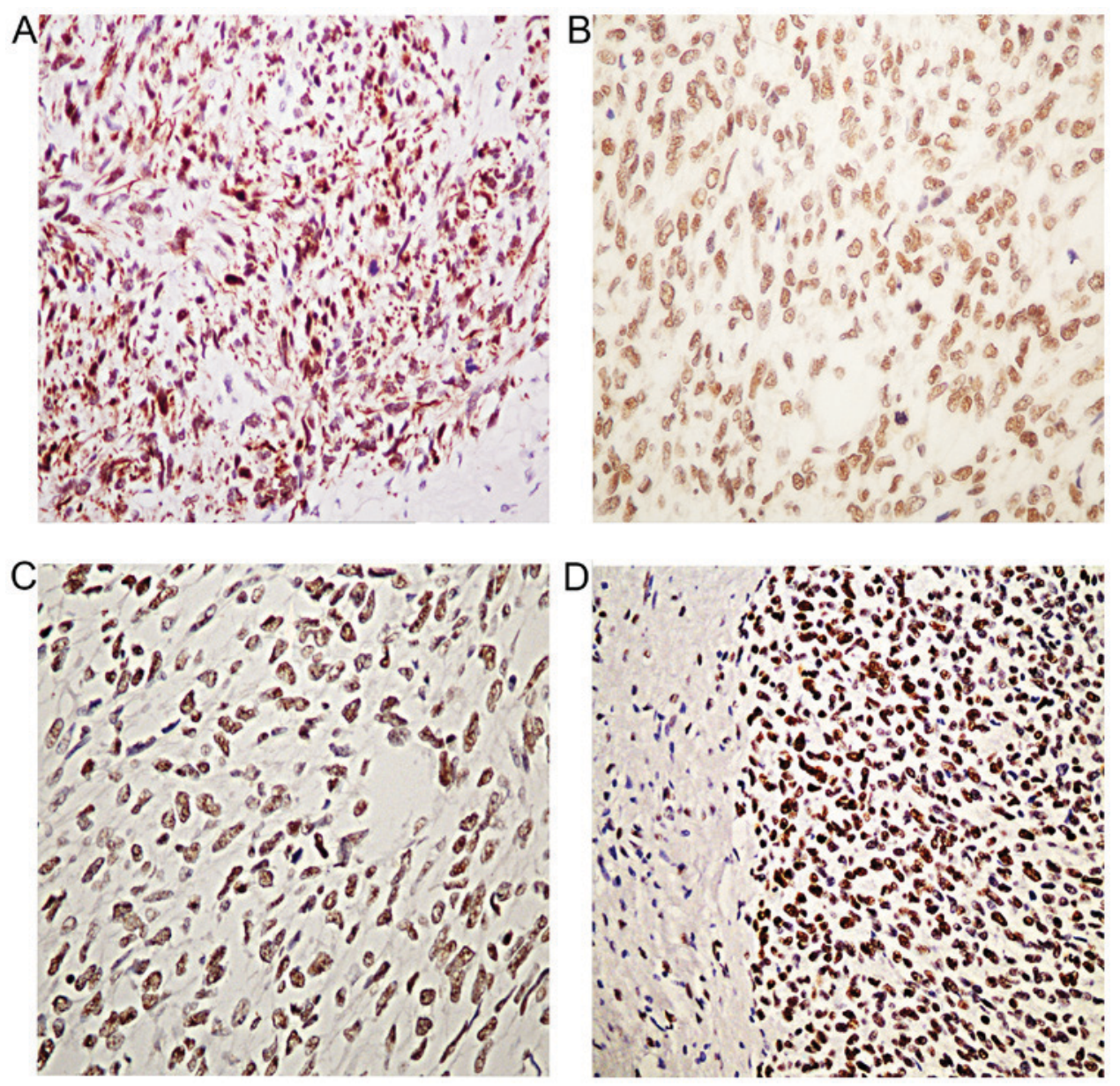

Figure 4. Immunohistochemistry of mismatch repair proteins for 1 case with instability in one marker. Slides were visualized using DAB and counterstained using hematoxylin. (A) mutL homolog 1, (B) PMS1 homolog 2, (C) MSH6 and (D) MSH2. Magnification, x200. MSH, mutS homolog.

mutations were alive with no evidence of cancer, compared with $25.4 \%$ of patients with KIT-mutations $(\mathrm{P}=0.010)$. All KIT exon 9-mutated cases exhibited tumor progression following imatinib treatment, while $44.4 \%$ of the KIT exon 11-mutated cases had stable disease subsequent to chemotherapy (data not shown).

Kaplan-Meier survival analysis revealed that, despite the absence of statistical significance, the 5-year overall survival rate was $66.1 \%$ for KIT-mutated cases, and $80 \%$ for PDGFRA and wild-type cases (Fig. 2). No significance was observed in recurrence-free survival analysis among KIT, PDGFRA and wild-type groups (data not shown).

MSI analysis. The MSI analysis was successful in all 79 GIST cases. A total of $75(\sim 95 \%)$ samples exhibited a stable profile, while 4 primary GISTs exhibited instability in one marker. In total, 2 cases exhibited alteration of the BAT-26 marker, 1 case exhibited alteration of the NR-21 marker and 1 case demonstrated instability in the BAT-25 marker (Fig. 3). Our previous study reported that the presence of instability in one marker in the Brazilian population may be due to polymorphic variants (36). Therefore, it was proposed that analysis of the MMR immunohistochemistry or the MSI analysis of paired normal DNA should be performed for these cases to accurately determine the MSI status of these patients. The investigation of MMR immunohistochemistry revealed positive staining for all MMR (MLH1, MSH2, MSH6 and PMS2) proteins analyzed (Fig. 4). In addition, the MSI analysis of paired normal DNA in all 4 cases revealed the same genotype in normal and tumor DNA. Thus, these results indicated that all 4 cases were MSS.

\section{Discussion}

Determination of MSI status appears to be a marker for novel treatments, and it may serve as a predictive marker for the selection of patients who may benefit from pembrolizumab, an anti-PD-1 immunotherapy (1). The data from this phase II trial support the hypothesis that MMR-deficient tumors are more responsive to PD-1 blockade compared with MMR-proficient tumors (1). However, there is still no data on clinical trials evaluating PD-1 agents in GISTs, despite the growing interest.

The MSI phenotype in GISTs is poorly-characterized and reports are not consensual. In the present study, MSI was analyzed in 79 GIST samples using a multiplex PCR comprising five quasi-monomorphic mononucleotide repeat markers. In the 4 cases that exhibited alteration in only one marker, MSI analysis was performed in paired normal DNA and MMR immunohistochemistry was performed, which revealed the MSS nature of these samples. Therefore, MSI was not present in the present series of GISTs. These findings are in accordance 
with the first study addressing the presence of MSI in GISTs by Lopes et al (31), which analyzed 33 GISTs. However, other authors reported the presence of MSI in 5\% (3/62) and 50\% $(10 / 22)$ of cases $(29,30)$.

It was proposed that these discrepant results may have several causes. First, the number of cases analyzed in the aforementioned two studies was too small for consistent results $(27,28)$. The present study examined 79 cases, which is the largest series that has undergone MSI status evaluation using molecular techniques. Secondly, distinct methodologies for MSI assessment were used, and the accuracy of MSI detection is known to be highly dependent on the techniques selected. Kose et al (30) used the BAT-26 marker in analysis of MSI, only in tumor DNA. Fukasawa et al (29) evaluated the loss of heterozygosity as well as MSI in paired normal and tumor DNA using dinucleotide markers dispersed on several chromosomes. Tissues were considered MSI-positive when one or more markers were altered. Notably, the two studies evaluated MSI in Japanese populations. This is particularly important due to the quasimonomorphic nature and the effect of the ancestry of the MSI markers. Buhard et al $(34,35)$ studied the global population and identified polymorphisms in the BAT-26 marker in up to $3.3 \%$ of the Asiatic populations, whereas in Caucasian populations this marker exhibited a monomorphic nature.

In GISTs, the molecular profile serves as a classification system that is useful for diagnostic, prognostic and treatment planning purposes $(19,22,38)$. In the present study, the KIT and PDGFRA profiles of the 79 GIST cases and their clinicopathological associations were similar to those previously reported in the literature (22). Mutations in KIT exon 11 were the most common oncogenic mutations observed in GISTs, followed by $K I T$ exon 9. Exon 18 was also revealed to be the most frequently mutated PDGFRA region. PDGFRA-mutant GISTs frequently possessed characteristics of low-risk GIST, including a gastric primary site and a low mitotic index, as previously reported in the literature $(19,22)$. In addition, a tendency for patients with PDGFRA mutations and those with wild-type GISTs to have a smaller risk of recurrence compared with patients with $K I T$ mutations was observed.

In conclusion, using accurate MSI methodologies widely used for the assessment of CRC, a large series of confirmed GISTs was analyzed for the presence of genetic instability phenotypes. No cases with MSI were observed, and so it was concluded that the MMR system is proficient in patients with GISTs, and that MSI does not appear to be involved in GIST tumorigenesis.

\section{Acknowledgements}

The present study was supported by The Brazilian National Council for Scientific and Technological Development (grant no. 476192/2013-7) and the São Paulo Research Foundation Doctoral Fellowship (grant no. 2013/25787-3).

\section{References}

1. Le DT, Uram JN, Wang H, Bartlett BR, Kemberling $\mathrm{H}$ Eyring AD, Skora AD, Luber BS, Azad NS, Laheru D, et al: PD-1 Blockade in tumors with mismatch-repair deficiency. N Engl J Med 372: 2509-2520, 2015.
2. Dudley JC, Lin MT, Le DT and Eshleman JR: Microsatellite instability as a biomarker for PD-1 blockade. Clin Cancer Res 22: 813-820, 2016.

3. Young J, Simms LA, Biden KG, Wynter C, Whitehall V, Karamatic R, George J, Goldblatt J, Walpole I, Robin SA, et al: Features of colorectal cancers with high-level microsatellite instability occurring in familial and sporadic settings: Parallel pathways of tumorigenesis. Am J Pathol 159: 2107-2116, 2001.

4. Miquel C, Jacob S, Grandjouan S, Aimé A, Viguier J, Sabourin JC, Sarasin A, Duval A and Praz F: Frequent alteration of DNA damage signalling and repair pathways in human colorectal cancers with microsatellite instability. Oncogene 26: 5919-5926, 2007.

5. Suraweera N, Duval A, Reperant M, Vaury C, Furlan D, Leroy K, Seruca R, Iacopetta B and Hamelin R: Evaluation of tumor microsatellite instability using five quasimonomorphic mononucleotide repeats and pentaplex PCR. Gastroenterology 123: 1804-1811, 2002.

6. Sinicrope FA and Sargent DJ: Molecular pathways: Microsatellite instability in colorectal cancer: Prognostic, predictive, and therapeutic implications. Clin Cancer Res 18: 1506-1512, 2012.

7. McCarter MD, Antonescu CR, Ballman KV, Maki RG, Pisters PW, Demetri GD, Blanke CD, von Mehren M, Brennan MF, McCall L, et al: Microscopically positive margins for primary gastrointestinal stromal tumors: Analysis of risk factors and tumor recurrence. J Am Coll Surg 215: 53-60, 2012.

8. Corless CL, Barnett CM and Heinrich MC: Gastrointestinal stromal tumours: Origin and molecular oncology. Nat Rev Cancer 11: 865-878, 2011

9. Doyle LA and Hornick JL: Gastrointestinal stromal tumours: From KIT to succinate dehydrogenase. Histopathology 64: 53-67, 2014.

10. Laurini JA and Carter JE: Gastrointestinal stromal tumors: A review of the literature. Arch Pathol Lab Med 134: 134-141, 2010.

11. Guller U, Tarantino I, Cerny T, Schmied BM and Warschkow R: Population-based SEER trend analysis of overall and cancer-specific survival in 5138 patients with gastrointestinal stromal tumor. BMC Cancer 15: 557, 2015.

12. Fregnani JH, de Oliveira AT, de Lima Vazquez V, Viana CR, Longatto-Filho A and Reis RM: Is the gastrointestinal stromal tumor arising in the rectovaginal septum an extragastrointestinal entity? A time for reflection. Int J Colorectal Dis 26: 387-389, 2011.

13. Joensuu H, Hohenberger P and Corless CL: Gastrointestinal stromal tumour. Lancet 382: 973-983, 2013.

14. Liegl-Atzwanger B, Fletcher JA and Fletcher CD: Gastrointestinal stromal tumors. Virchows Arch 456: 111-127, 2010.

15. Miettinen $\mathrm{M}$ and Lasota J: Gastrointestinal stromal tumors: Pathology and prognosis at different sites. Semin Diagn Pathol 23: 70-83, 2006.

16. Stamatakos M, Douzinas E, Stefanaki C, Safioleas P, Polyzou E, Levidou G and Safioleas M: Gastrointestinal stromal tumor. World J Surg Oncol 7: 61, 2009.

17. Joensuu H, Martin-Broto J, Nishida T, Reichardt P, Schöffski P and Maki RG: Follow-up strategies for patients with gastrointestinal stromal tumour treated with or without adjuvant imatinib after surgery. Eur J Cancer 51: 1611-1617, 2015.

18. Hirota S, Isozaki K, Moriyama Y, Hashimoto K, Nishida T, Ishiguro S, Kawano K, Hanada M, Kurata A, Takeda M, et al: Gain-of-function mutations of c-kit in human gastrointestinal stromal tumors. Science 279: 577-580, 1998.

19. Joensuu H, Rutkowski P, Nishida T, Steigen SE, Brabec P, Plank L, Nilsson B, Braconi C, Bordoni A, Magnusson MK, et al: KIT and PDGFRA mutations and the risk of GI stromal tumor recurrence. J Clin Oncol 33: 634-642, 2015.

20. Braggio E, Braggio Dde A, Small IA, Lopes LF, Valadão M, Gouveia ME, Moreira Ados S, Linhares E, Romano S, Bacchi CE, et al: Prognostic relevance of KIT and PDGFRA mutations in gastrointestinal stromal tumors. Anticancer Res 30: 2407-2414, 2010.

21. Rubin BP and Heinrich MC: Genotyping and immunohistochemistry of gastrointestinal stromal tumors: An update. Semin Diagn Pathol 32: 392-399, 2015.

22. Barnett CM, Corless CL and Heinrich MC: Gastrointestinal stromal tumors: Molecular markers and genetic subtypes. Hematol Oncol Clin North Am 27: 871-888, 2013.

23. Agaimy A, Terracciano LM, Dirnhofer S, Tornillo L, Foerster A, Hartmann A and Bihl MP: V600E BRAF mutations are alternative early molecular events in a subset of KIT/PDGFRA wild-type gastrointestinal stromal tumours. J Clin Pathol 62: 613-616, 2009. 
24. Martinho O, Gouveia A, Viana-Pereira M, Silva P, Pimenta A, Reis RM and Lopes JM: Low frequency of MAP kinase pathway alterations in KIT and PDGFRA wild-type GISTs. Histopathology 55: 53-62, 2009.

25. Campanella NC, de Oliveira AT, Scapulatempo-Neto C, Guimarães DP and Reis RM: Biomarkers and novel therapeutic targets in gastrointestinal stromal tumors (GISTs). Recent Pat Anticancer Drug Discov 8: 288-297, 2013.

26. Mol CD, Dougan DR, Schneider TR, Skene RJ, Kraus ML, Scheibe DN, Snell GP, Zou H, Sang BC and Wilson KP: Structural basis for the autoinhibition and STI-571 inhibition of c-Kit tyrosine kinase. J Biol Chem 279: 31655-31663, 2004.

27. Tan CB, Zhi W, Shahzad G and Mustacchia P: Gastrointestinal stromal tumors: A review of case reports, diagnosis, treatment and future directions. ISRN Gastroenterol 2012: 595968, 2012.

28. Rossi S, Gasparotto D, Miceli R, Toffolatti L, Gallina G, Scaramel E, Marzotto A, Boscato E, Messerini L, Bearzi I, et al: KIT, PDGFRA, and BRAF mutational spectrum impacts on the natural history of imatinib-naive localized GIST: A population-based study. Am J Surg Pathol 39: 922-930, 2015.

29. Fukasawa T, Chong JM, Sakurai S, Koshiishi N, Ikeno R, Tanaka A, Matsumoto Y, Hayashi Y, Koike M and Fukayama M: Allelic loss of 14q and 22q, NF2 mutation, and genetic instability occur independently of c-kit mutation in gastrointestinal stromal tumor. Jpn J Cancer Res 91: 1241-1249, 2000.

30. Kose K, Hiyama T, Tanaka S, Yoshihara M, Yasui W and Chayama K: Nuclear and mitochondrial DNA microsatellite instability in gastrointestinal stromal tumors. Pathobiology 73 : 93-97, 2006.

31. Lopes JM, Silva P, Seixas M, Cirnes L and Seruca R: Microsatellite instability is not associated with degree of malignancy and p53 expression of gastrointestinal stromal tumours. Histopathology 33: 579-581, 1998.
32. de Oliveira AT, Pinheiro C, Longatto-Filho A, Brito MJ, Martinho O, Matos D, Carvalho AL, Vazquez VL, Silva TB, Scapulatempo C, et al: Co-expression of monocarboxylate transporter 1 (MCT1) and its chaperone (CD147) is associated with low survival in patients with gastrointestinal stromal tumors (GISTs). J Bioenerg Biomembr 44: 171-178, 2012.

33. de Oliveira AT, Reis RM, Afonso J, Martinho O, Matos D, Carvalho AL, Vazquez VL, Silva TB, Scapulatempo C, Saad SS and Longatto-Filho A: Lymphangiogenic VEGF-C and VEGFR-3 expression in genetically characterised gastrointestinal stromal tumours. Histol Histopathol 26: 1499-1507, 2011.

34. Buhard O, Cattaneo F, Wong YF, Yim SF, Friedman E, Flejou JF, Duval A and Hamelin R: Multipopulation analysis of polymorphisms in five mononucleotide repeats used to determine the microsatellite instability status of human tumors. J Clin Oncol 24: 241-251, 2006.

35. Buhard O, Suraweera N, Lectard A, Duval A and Hamelin R: Quasimonomorphic mononucleotide repeats for high-level microsatellite instability analysis. Dis Markers 20: 251-257, 2004.

36. Campanella NC, Berardinelli GN, Scapulatempo-Neto C, Viana D, Palmero EI, Pereira R and Reis RM: Optimization of a pentaplex panel for MSI analysis without control DNA in a Brazilian population: Correlation with ancestry markers. Eur J Hum Genet 22: 875-880, 2014.

37. Campanella NC, Penna V, Ribeiro G, Abrahão-Machado LF, Scapulatempo-Neto C and Reis RM: Absence of microsatellite instability in soft tissue sarcomas. Pathobiology 82: 36-42, 2015 ,

38. Corless CL: Gastrointestinal stromal tumors: What do we know now? Mod Pathol 27 (Suppl 1): S1-S16, 2014 